\title{
2-D Physical Modeling to Measure the Effectiveness of Perforated Skirt Breakwater for Short-Period Waves
}

\author{
Harman Ajiwibowo \\ Ocean Engineering Program, Faculty of Civil and Environmental Engineering \\ Bandung Institute of Technology \\ Email: ajiwibowoh@yahoo.com
}

\begin{abstract}
The effectiveness of a breakwater can be measured by quantifying the transmission coefficient $\left(\mathrm{K}_{\mathrm{T}}\right)$. The smaller the coefficient, the better the performance of the breakwater. A physical modeling on the proposed breakwater was conducted to identify the coefficient of Perforated Skirt Breakwater (PSB). The PSB model was tested in 2-D wave flume at Ocean Wave Research Laboratory FTSL ITB, to obtain the effectiveness of PSB for short-period waves (prototype periods, $\mathrm{Tp}=4$ second and smaller). The scaling of PSB models applies the principle of Froude Similarity, where the Froude number in model equals to the Froude number in prototype $\left(\mathrm{Fr}_{\mathrm{m}}=\mathrm{Fr}_{\mathrm{p}}\right)$. The flume is equipped with 5 resistance-type wave probes and 8-channel DAS (Data Acquisition System). Wave heights $(\mathrm{H})$ and wave periods $(\mathrm{T})$ data were observed both manually by visual observation and wave probes readings (processed later with method of "zero mean up-crossing" technique). The incoming wave heights $\left(\mathrm{H}_{\mathrm{i}}\right)$ and transmitted wave heights $\left(\mathrm{H}_{\mathrm{t}}\right)$ were measured and processed to obtain the transmission coefficient $\left(\mathrm{K}_{\mathrm{T}}\right)$. The relationships between $\mathrm{K}_{\mathrm{T}}$ and nondimensional variables (skirt draft / incident wave height, $\mathrm{S} / \mathrm{H}_{\mathrm{i}}$ ) are analyzed and the calculated effectiveness of the PSB for varied environmental condition is obtained to be up to $70 \%$.
\end{abstract}

Keywords: non-dimensional variables; perforated skirt breakwater; short-period waves; transmission coefficient.

\section{$1 \quad$ Introduction}

The Liquid Natural Gas (LNG) Exploration site at Bintuni Bay, West Papua, has a combo dock facility that is operated to allow berthing ship to load LNG from the refinery site. Berthing activities will require a calm wave condition, where these conditions will be achieved by constructing a breakwater protecting the harbor. The depth of water around the port is about $6-9 \mathrm{~m}$.

Rubble mound breakwater is costly when applied in deep water due to its construction volume in deep water, thus it is not recommended in this situation. To handle the cost problem, the proposed design for the breakwater is Perforated Skirt Breakwater (PSB). In order to reduce the cost, PSB uses piles to support the upper structure. At the upper structure (around the water surface), 
there are some important parts that distinguish PSB from the other types of breakwater. The major components are 1) concrete skirts attached to the piles, 2) chambers which also help dissipate the wave energy. For PSB model, the skirts are separated from the main structure of PSB. The skirts are designed to be easily moved up and down, to adjust the value of breakwater draft $(\mathrm{S})$. The illustration of skirts, chambers, portals and several parameters of PSB can be seen in Figure 3 to Figure 7.

The effectiveness of the breakwater depends on the transmission coefficient $\left(\mathrm{K}_{\mathrm{T}}\right)$, which is influenced by several physical parameters, such as skirts of breakwater (which affect the draft of the breakwater S) and length of chamber (Lc). The smaller the coefficient, the better the performance of the breakwater. PSB model was designed and tested in 2-D wave flume at Ocean Wave Research Laboratory FTSL ITB, Bandung Indonesia. 2-D wave flume dimensions are: 40 meters of length; $1,2 \mathrm{~m}$ of width; and 1,5m of height. The waves were generated by a piston-type wave generator that can generate regular waves up to $30 \mathrm{~cm}$ of wave height. The wave flume is also equipped by 5 wave probes and 8 channels of DAS (Data Acquisition System). The investigation was limited to regular waves.

Since it was introduced by Jarlan [1], perforated breakwater has been widely used to reduce the wave forces on the front of the vertical wall breakwater (Quinn, [2]). The front section of perforated breakwater is facing the open sea with perforated part, while at the behind section is designed from solid and impermeable structure (illustration of perforated breakwater can be seen in Figure 1). One important characteristic of the perforated breakwater is the wave energy will be dissipated without great effect on reflecting waves. Performance of perforated breakwater is depending on the porosity of the outer wall and relative chamber width to wavelength. Other parameters such as wave's height, period, regularity of waves, wave's direction and water depth also affected.

Pressure waves in hollow walls (perforated wall) are less than a solid wall, as has been found by Bergmann and Oumeraci [3]. A research was conducted by Armono and Hall [4] for wave transmission at submerged breakwater, which made of artificial coral reefs named as Hollow Hemispherical Shape Artificial Reefs (HSAR). Investigation was also conducted by Ariyarathne [5] with the results agree well with Kondo [6], Suh et al. [7] and Hagiwara [8]. 


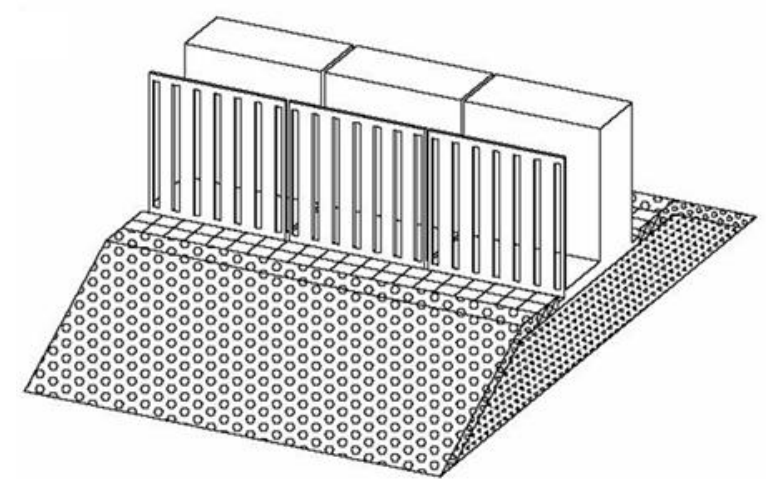

Figure 1 Perforated breakwater (introduced by Jarlan [1]).

As an example, for the application of perforated breakwater is Raffles Marina Wharf, by Bloxam [9], as shown in Figure 2. Raffles Marina is at Tuas on the western coast of Singapore, just south of the Second Crossing Bridge to Malaysia.

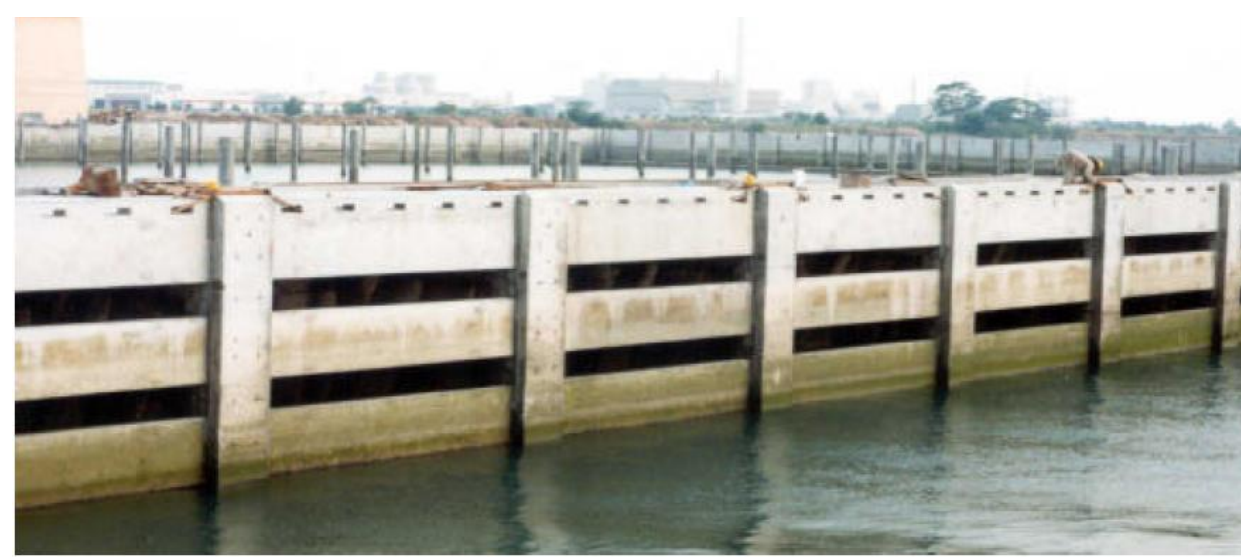

Figure 2 Example of the application of perforated breakwater (Raffles Marina Wharf/breakwater in Singapore).

There are few modifications within the chambers, in which they were given additional perforated walls and the rear wall being solid wall. Hereafter this structure named as Perforated Skirt Breakwater (PSB).

The PSB provides an additional alternative type of breakwater in the field of Coastal Protections Scheme. The various benefits of PSB, namely: 
1. PSB has economic value (when applied in deep water).

2. PSB can reduce the effects of wave reflection.

3. PSB can be used as an alternative breakwater in the area with no stone material for the construction, as happened in South Papua such as Merauke, Indonesia.

\section{Material, Model, and Methods}

\subsection{Material}

The model was made by wood materials.

\subsection{Model}

The skirt parts of the PSB were designed to be easily moved up and down, to adjust the value of breakwater draft (S). Draft of breakwater is a distance from the surface of the water to the bottom part of the skirts (see Figure 5). The illustration of skirts, chambers, portals and several parameters of PSB can be seen in Figure 3 to Figure 7.

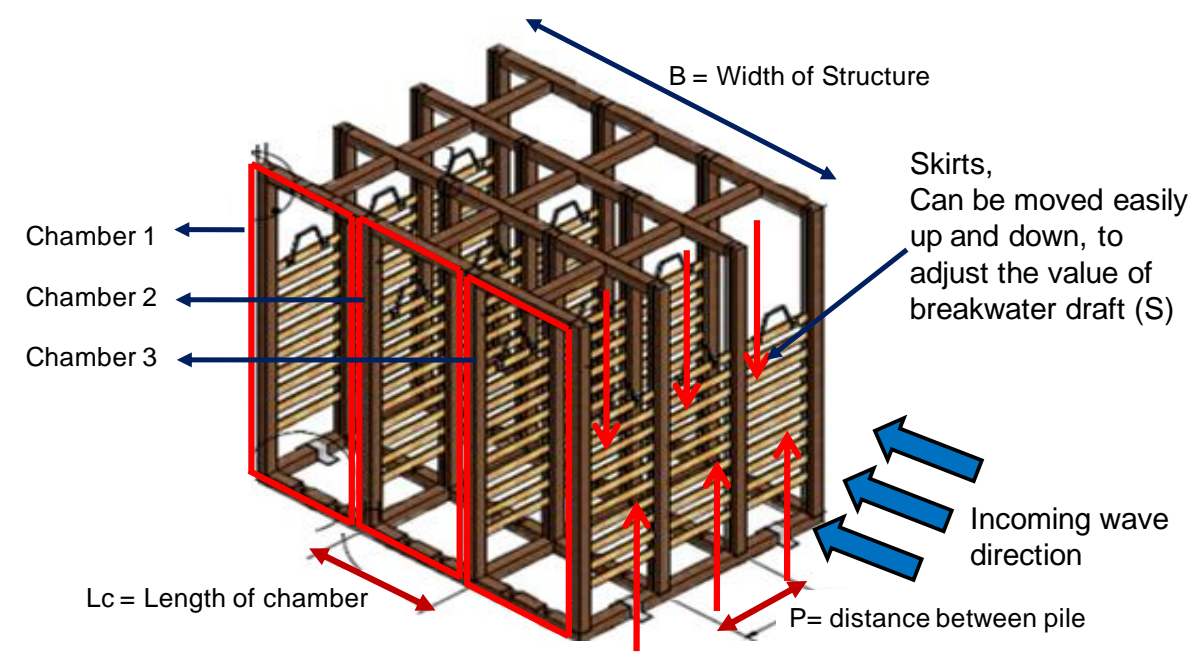

Figure 3 Some important parameters on the PSB.

PSB has several filtering portals with skirts at each portal (see Figure 4). The position of each skirt is alternated between the adjacent filtering portals. 


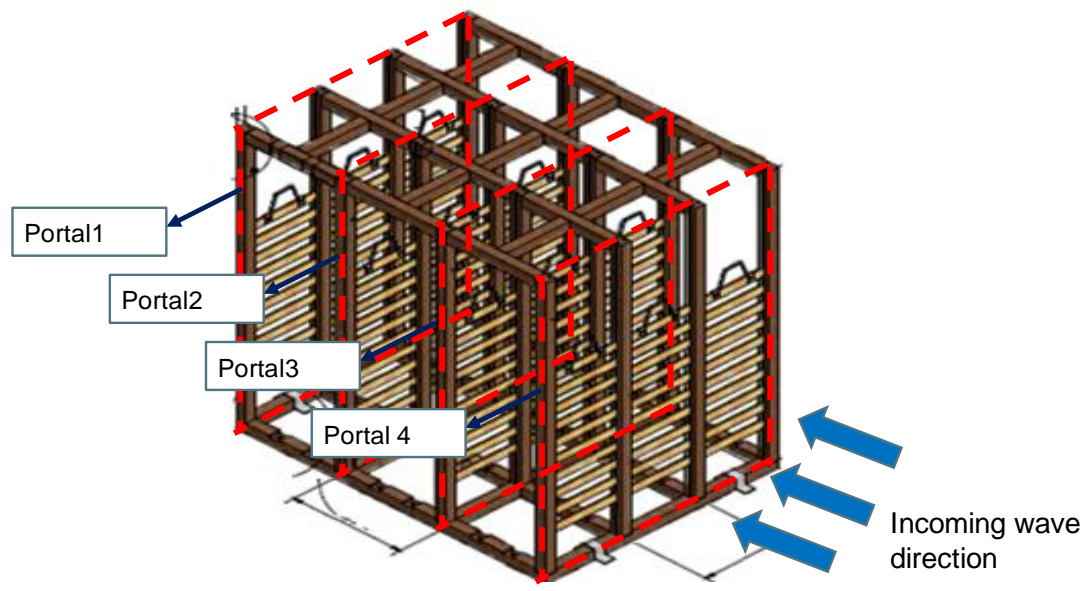

Figure 4 Definition of portal parameter on the PSB.

In laboratory tests, draft of the breakwater (S) can be adjusted by lowering or raising the skirts. The sketch of the adjustment of the draft by skirts can be seen in Figure 5.

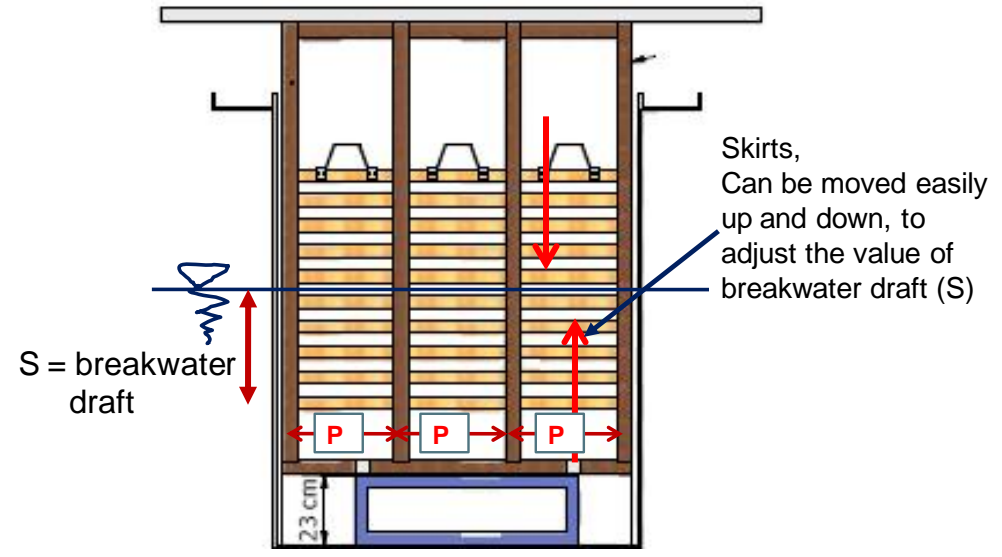

Figure 5 Sketch of draft adjustment (front view). 


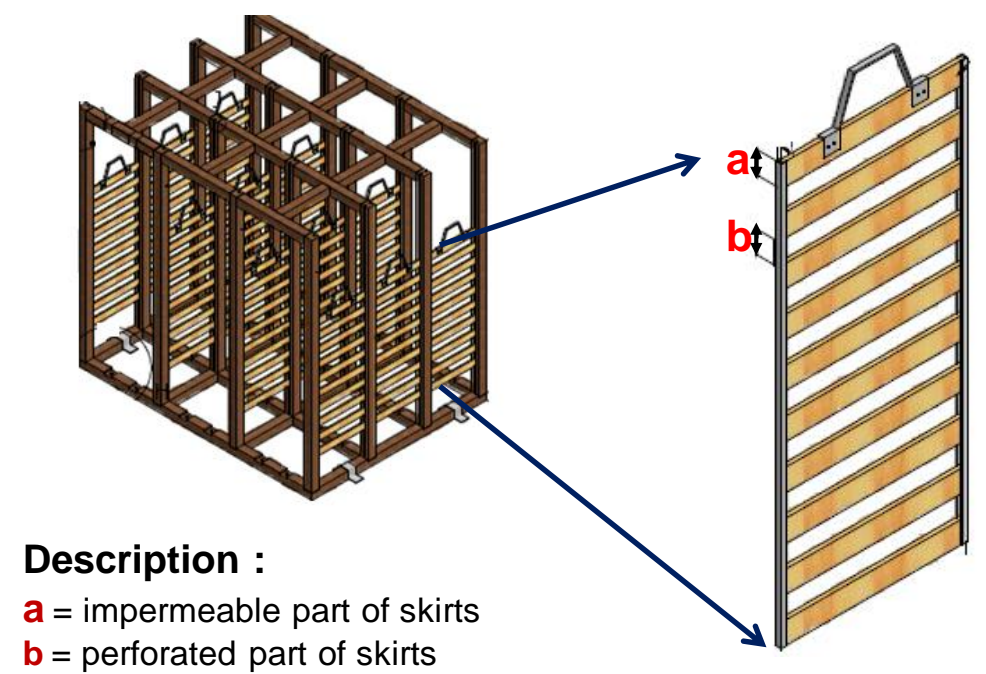

Figure 6 Sketch of skirts on PSB.

Figure 7 shows the side view of PSB in wave flume.

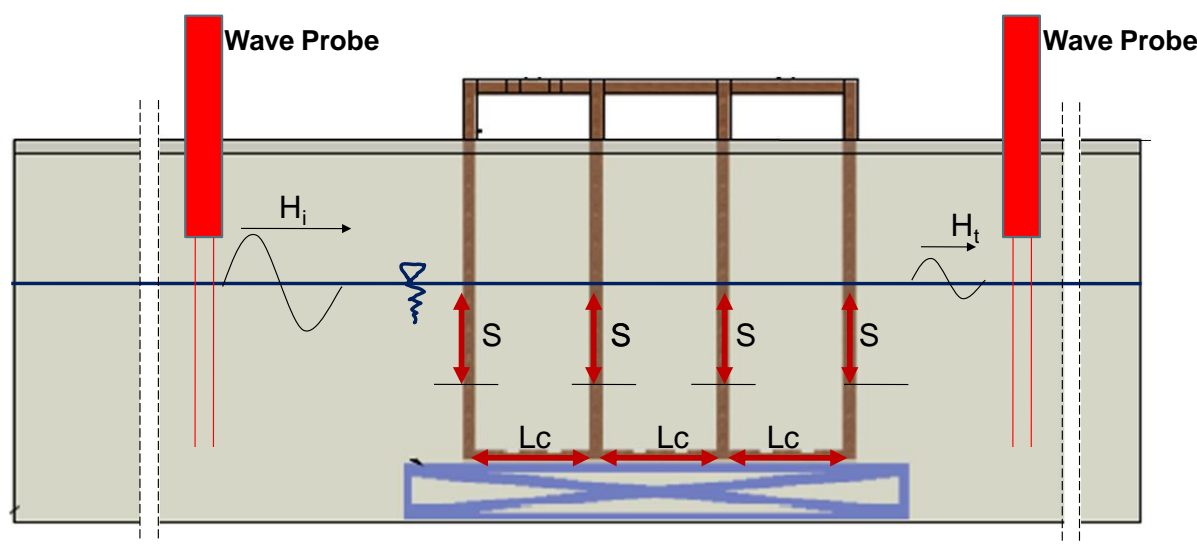

Figure 7 Sketch of PSB model (side view)

Figure 8 shows the PSB in the wave flume subjected to regular waves 


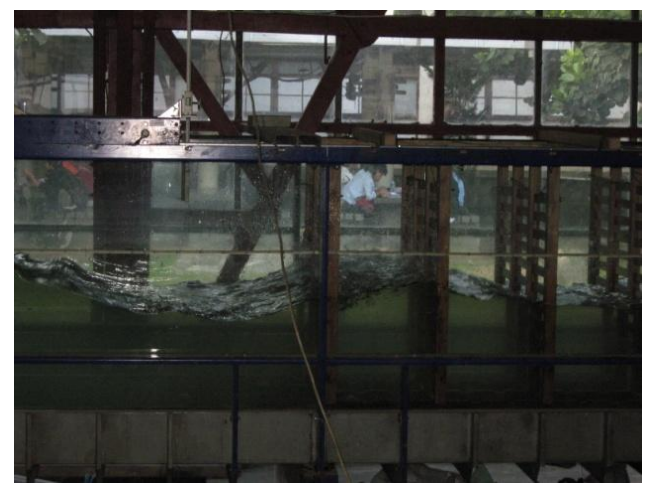

Figure 8 2-D physical modeling on PSB in Ocean Wave Research Laboratory, ITB.

\subsection{Methods}

\subsubsection{Scaling}

The scaling of PSB model applies the principle of Froude Similarity where scale and similarity model selection follow Froude similarity defined as:

$$
\begin{gathered}
F_{r_{m}}=F_{r_{p}} \\
{\left[\frac{v}{\sqrt{g L}}\right]_{m}=\left[\frac{v}{\sqrt{g L}}\right]_{p}}
\end{gathered}
$$

Length scale ratio is defined as $\mathrm{N}_{\mathrm{L}}=\mathrm{L}_{\mathrm{p}} / \mathrm{L}_{\mathrm{m}}$. Subscripts $\mathrm{p}$ is prototype and $\mathrm{m}$ is model. The determination of scaling was adjusted to the ability and capacity of wave flume compared to the size of the prototype. The maximum prototype water depth is $9 \mathrm{~m}$ and the maximum depth that can be optimally operated in the wave flume is $75 \mathrm{~cm}$, so the scale would be $75 \mathrm{~cm}: 900 \mathrm{~cm}$ or approximately $1: 12$. Using this scale, if the prototype wave height is $2.6 \mathrm{~m}$; then the model wave height would be $2.6 / 12=21.7 \mathrm{~cm}$. Using Froude similarity, the other scaling quantity, i.e. time scale and weight scale can be written as Length Scale $=\mathrm{N}_{\mathrm{L}}=12$; Time Scale $=1:\left(\mathrm{N}_{\mathrm{L}}\right)^{0,5}=1: 3,5$ and Weight Scale $=1:\left(\mathrm{N}_{\mathrm{L}}\right)^{3}=1: 12^{3}=$ 1:1728. Based on these scales, model dimensions are presented in Table 1. The width of model is limited to wave flume width of $120 \mathrm{~cm}$. Hence, there was only three column of chamber used in testing which the total width of column is set to be $116 \mathrm{~cm}$, so distance between piles was limited to $38.7 \mathrm{~cm}$ on model scale. 
Table 1 Scenario of experiments (based on model dimensions).

\begin{tabular}{cccc}
\hline Dimension & Symbol & Prototype (m) & Model (cm) \\
\hline \multirow{3}{*}{ Length of Chamber } & Lc & 2.0 & 16.7 \\
& Lc & 4.0 & 33.3 \\
Number of Chambers & Lc & 6.0 & 50.0 \\
& Nc & 3 (dimensionless) & 3 (dimensionless) \\
& Nc & 2(dimensionless) & 2 (dimensionless) \\
Draft of Breakwater & $\mathrm{S}$ & 1.0 & 8.3 \\
Distance Between Piles & $\mathrm{S}$ & 2.0 & 16.7 \\
Skirts Type 1 & $\mathrm{S}$ & 4.0 & 33.3 \\
& $\mathrm{P}$ & 5.0 & 38.7 \\
Skirts Type 2 & $\mathrm{a}$ & 0.5 & 4.2 \\
& $\mathrm{~b}$ & 0.5 & 4.2 \\
& $\mathrm{a}$ & 0.7 & 6.0 \\
\hline
\end{tabular}

The scenario consists of 2 parts (based on number of chambers $\mathrm{Nc}$ ):

1. Experiment with number of chambers $(\mathrm{Nc})=3$ chambers

In this scenario, all parameters of PSB dimensions were conducted in the laboratory.

2. Experiment with number of chambers $(\mathrm{Nc})=2$ chambers

In this scenario, parameters of PSB dimensions were selected and limited only for certain conditions, i.e. Lc prototype $=5 \mathrm{~m}$ or Lc model $=41.7 \mathrm{~cm}$ and only using skirt type 2 on the experiment.

There are two types of skirt unit (based on dimension of $a$ and $b$ variables):

1. Skirt type 1

$\mathrm{a}=$ width of skirt $=0.5 \mathrm{~m}$ on prototype $(\mathrm{a}=4.2 \mathrm{~cm}$ on model $)$

$\mathrm{b}=$ gap between skirt $=0.5 \mathrm{~m}$ on prototype $(\mathrm{a}=4.2 \mathrm{~cm}$ on model $)$

2. Skirt type 2

$\mathrm{a}=$ width of skirt $=0.7 \mathrm{~m}$ on prototype $(\mathrm{a}=6.0 \mathrm{~cm}$ on model $)$

$\mathrm{b}=$ gap between skirt $=0.3 \mathrm{~m}$ on prototype $(\mathrm{a}=2.4 \mathrm{~cm}$ on model $)$

While for environmental conditions, the scaling is presented in Table 2.

Table 2 Scenario of experiments (based on environmental conditions).

\begin{tabular}{cccc}
\hline Dimension & Symbol & Prototype & $\begin{array}{c}\text { Model } \\
\text { (Scale 1:12) }\end{array}$ \\
\hline Water Depth & $\mathrm{h}$ & $9.0 \mathrm{~m}$ & $75.0 \mathrm{~cm}$ \\
Incident Wave & $\mathrm{H}_{\mathrm{i}}$ & $1.5 \mathrm{~m}$ & $12.5 \mathrm{~cm}$ \\
Height & $\mathrm{H}_{\mathrm{i}}$ & $2.0 \mathrm{~m}$ & $16.7 \mathrm{~cm}$ \\
Wave Period & $\mathrm{H}_{\mathrm{i}}$ & $2.6 \mathrm{~m}$ & $21.7 \mathrm{~cm}$ \\
& $\mathrm{~T}$ & $4.0 \mathrm{~s}$ & $1.2 \mathrm{~s}$ \\
\hline
\end{tabular}


Table 1 and Table 2 show the scenario of the experiments, where length of chamber $(\mathrm{Lc})$, skirt model, incident wave height $\left(\mathrm{H}_{\mathrm{i}}\right)$, skirt draft $(\mathrm{S})$ were varied to a fixed wave period ( $\mathrm{T}_{\mathrm{p}}=4$ seconds), where it's categorized as short-period waves.

\subsubsection{Model Set Up}

There were 5 wave probes placed in the wave flume. PSB model was placed between probe 3 and probe 4 (see Figure 9).

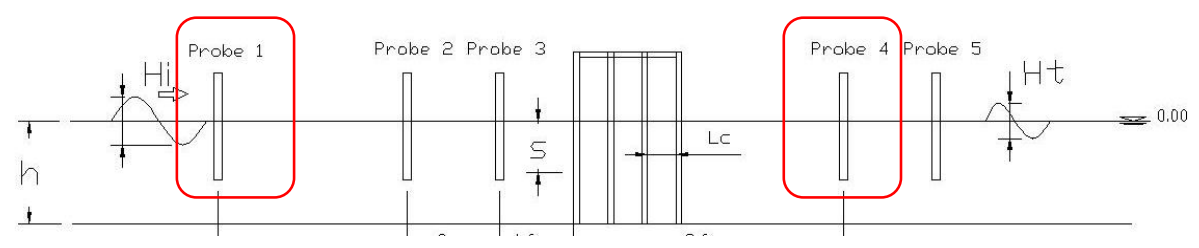

Figure 9 Definition sketch and set up of model in the 2D-wave flume.

\subsubsection{Wave Heights $(\mathrm{H})$ and periods $(\mathrm{T})$}

Data were taken from wave probes 1, 2, 3, 4 and 5 (see Figure 9). Data from wave probe 1 is of incident wave height $\left(\mathrm{H}_{\mathrm{i}}\right)$, wave probe 2 and wave probe 3 data are used for analyzing the wave reflection $\left(\mathrm{H}_{\mathrm{r}}\right)$, while wave probe 4 and wave probe 5 data are of transmitted waves $\left(\mathrm{H}_{\mathrm{T}}\right)$. However, the reflected coefficient was not a topic in this paper. Wave height $(\mathrm{H})$ and period $(\mathrm{T})$ data were observed both manually by visual observation and digitally from wave probes and data acquisition software (i.e. processed later with method of zero mean up-crossing technique). Unprocessed data obtained from the wave probes is in the form of resistance quantity, then using software program, these data are converted to time series of water surface. The procedure to obtain data can be written as follows:

1. Extracting recorded data from probe.

2. Zero mean processing the extracted data.

3. Observing the resulted time series to decide best data range before the timeseries are affected by wave reflections.

4. Up-crossing the time series to get the wave heights and periods.

5. Averaging the Wave Heights $\left(\bar{H}_{i}\right)$ for time series range in step 3 .

\subsubsection{Transmission Coefficient $\left(K_{T}\right)$}

Take the ratio of $\mathrm{H}_{\mathrm{T}}$ (transmitted waves) from wave probe 4 and $\mathrm{H}_{\mathrm{i}}$ (incident wave height ) from wave probe 1 (illustrated by Figure 9), and the transmission coefficient can be written as, 


$$
K_{T}=\frac{H_{T}}{H_{i}}
$$

\section{Dimensional Analysis}

To present the experimental results in simpler form, dimensional analysis is conducted to obtain some non-dimensional quantities. The following nondimensional variables are obtained,

$$
K_{T}=f\left(\frac{H_{i}}{g T^{2}}, \frac{h}{g T^{2}}, \frac{S}{g T^{2}}, \frac{L c}{g T^{2}}, \frac{b}{g T^{2}}, \frac{P}{g T^{2}}\right)
$$

\section{$4 \quad$ Results and Discussion}

\subsection{Transmission Coefficient $\left(K_{T}\right)$ vs Breakwater Draft/Incident Wave Height $\left(\mathbf{S} / \mathbf{H}_{\mathbf{i}}\right)$}

Figures 10 to 12 show the plot of $\mathrm{K}_{\mathrm{T}}$ against the breakwater draft /incident wave height $\left(\mathrm{S} / \mathrm{H}_{\mathrm{I}}\right)$ for PSB investigation, for various scenarios of experiment (Table 1 and Table 2) with short-period waves $\left(\mathrm{T}_{\mathrm{p}}=4 \mathrm{~s}\right.$ or $\left.\mathrm{T}_{\mathrm{m}}=1,2 \mathrm{~s}\right)$.

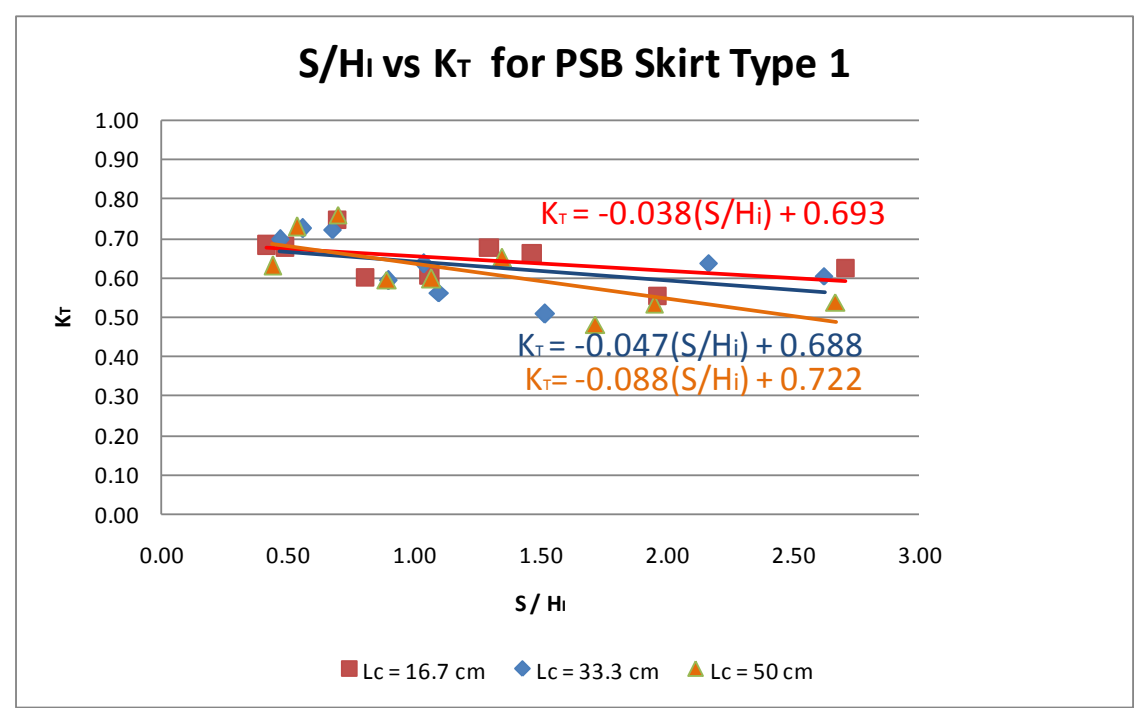

Figure 10 Transmission coefficient $\left(K_{T}\right)$ vs $S / H_{i}$ for PSB Type $1, T_{p}=4 \mathrm{~s}$ or $\mathrm{T}_{\mathrm{m}}=1.2 \mathrm{~s}$ for $\mathrm{Nc}=3$ chambers 


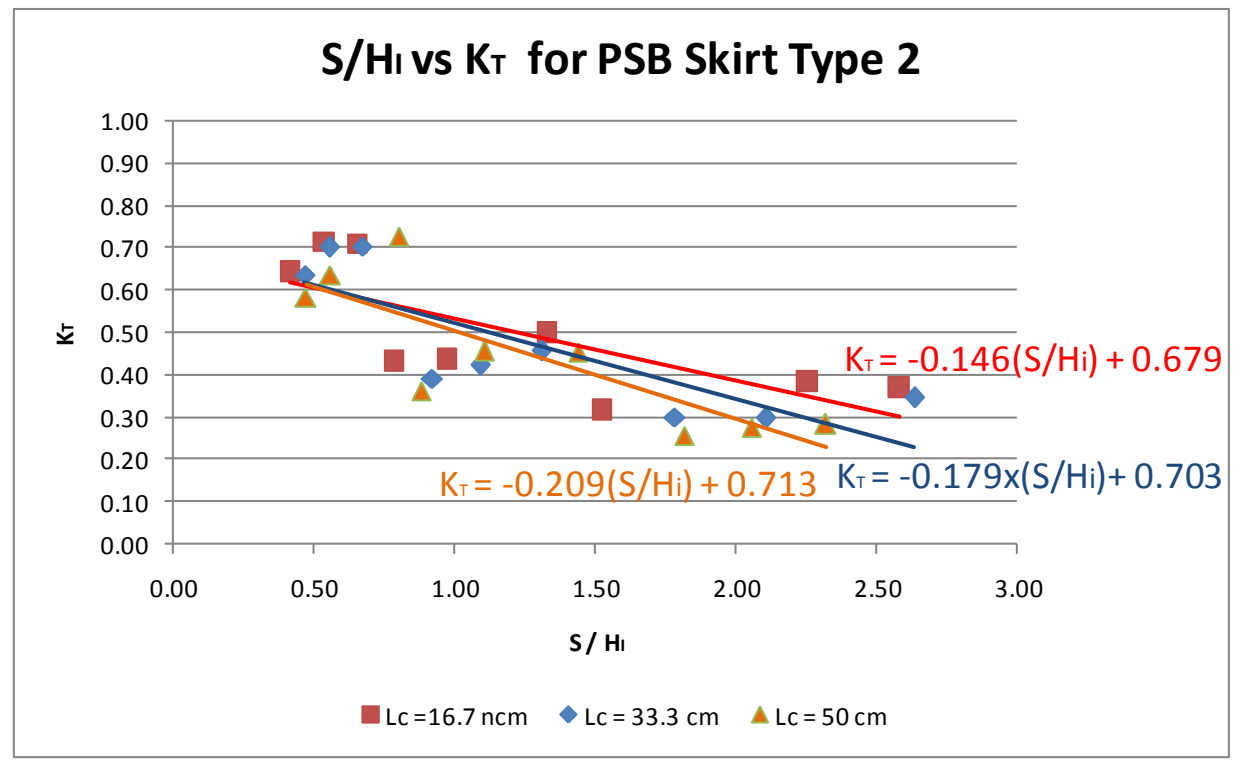

Figure 11 Transmission coefficient $\left(\mathrm{K}_{\mathrm{T}}\right) \mathrm{vs} \mathrm{S} / \mathrm{H}_{\mathrm{i}}$ for PSB Type $2, \mathrm{~T}_{\mathrm{p}}=4 \mathrm{~s}$ or $\mathrm{T}_{\mathrm{m}}=1.2 \mathrm{~s}$ for $\mathrm{Nc}=3$ chambers.

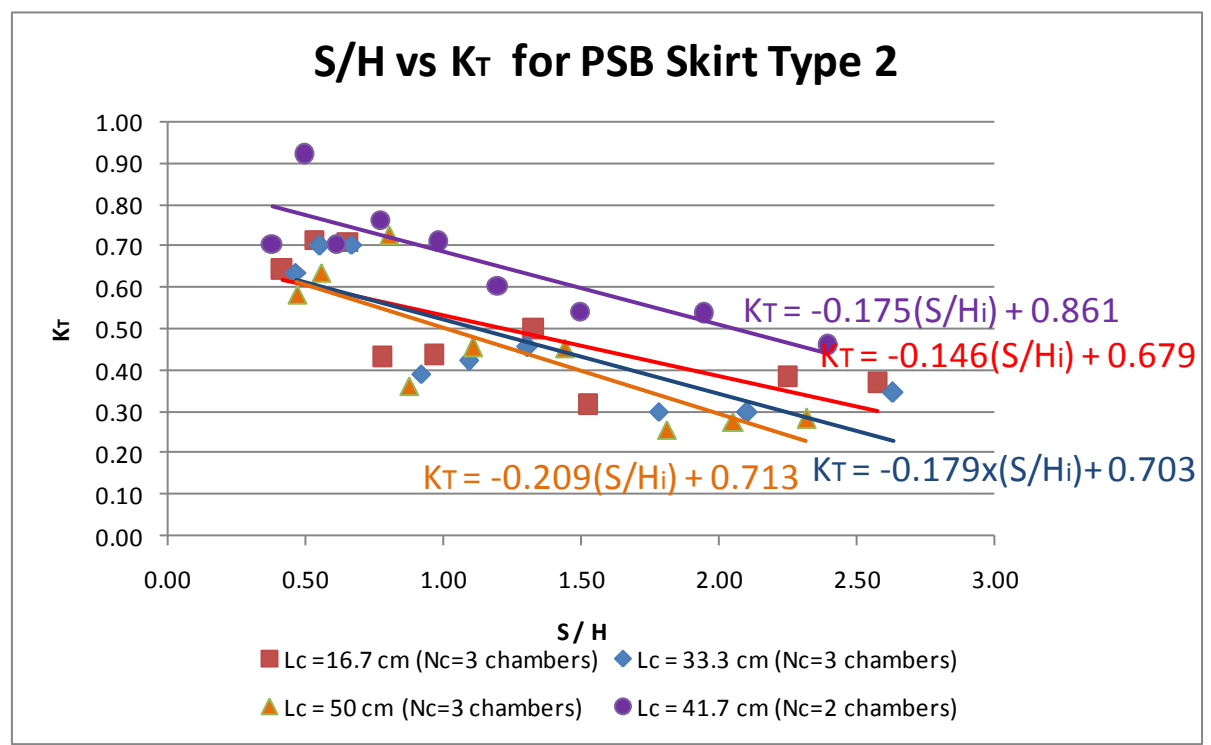

Figure 12 Transmission coefficient $\left(\mathrm{K}_{\mathrm{T}}\right) \mathrm{vs} \mathrm{S} / \mathrm{H}_{\mathrm{i}}$ for PSB Type $2, \mathrm{~T}_{\mathrm{p}}=4 \mathrm{~s}$ or $\mathrm{T}_{\mathrm{m}}=1.2 \mathrm{~s}$ for $\mathrm{Nc}=3$ chambers and $\mathrm{Nc}=2$ chambers. 
Comparing results in Figures 10 and 11, it can be concluded that the skirt type 2 is more effective than a skirt type 1 .

Figure 12 shows review for all experiments (including the comparison between $\mathrm{Nc}=3$ chambers and $\mathrm{Nc}=2$ chambers).

Based on Figure 12, it can be concluded that number of chamber $(\mathrm{Nc})=3$ is better than number of chamber $(\mathrm{Nc})=2$ chambers.

\subsection{Other Non-Dimensional Products}

Figures 13 to 16 show non-dimensional relationship for each skirt model (skirt model 1 and skirt model 2).

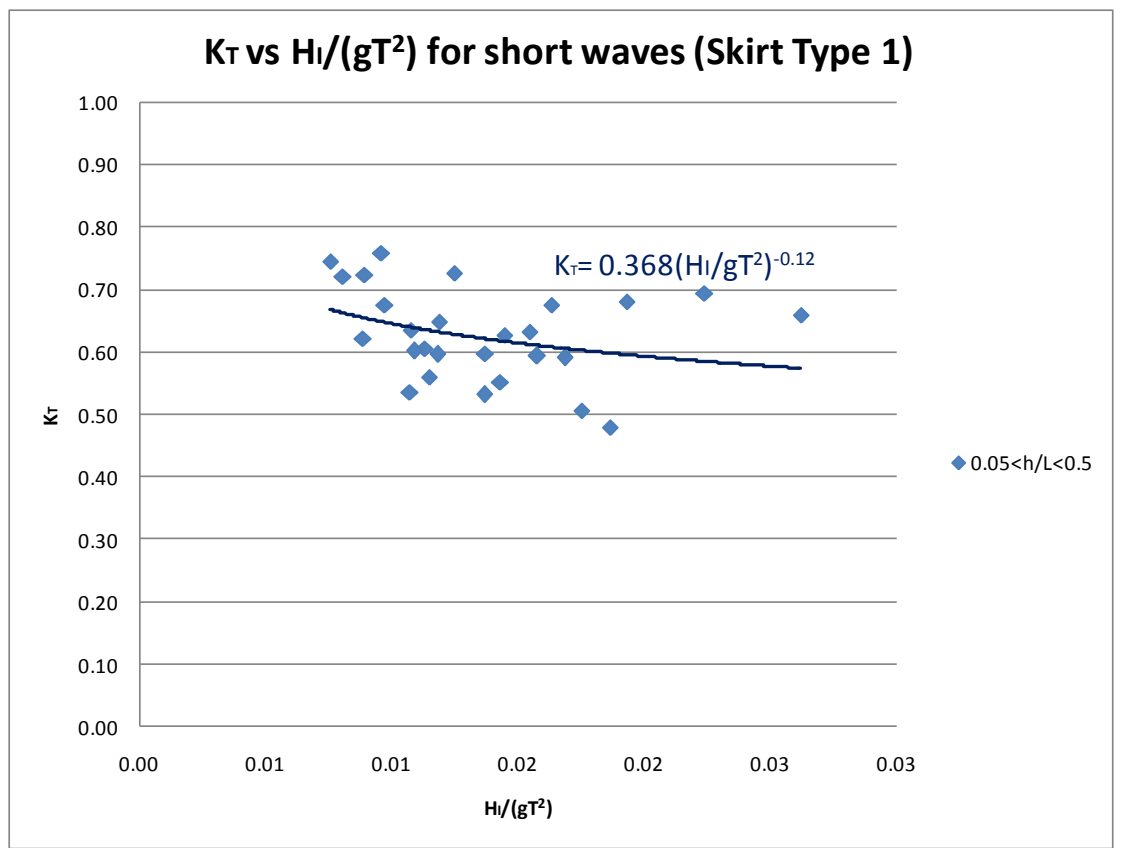

Figure $13 \mathrm{~K}_{\mathrm{T}}$ vs $\mathrm{H}_{\mathrm{i}} /\left(\mathrm{gT}^{2}\right)$ for medium depth criteria on PSB skirt type 1 investigation. 


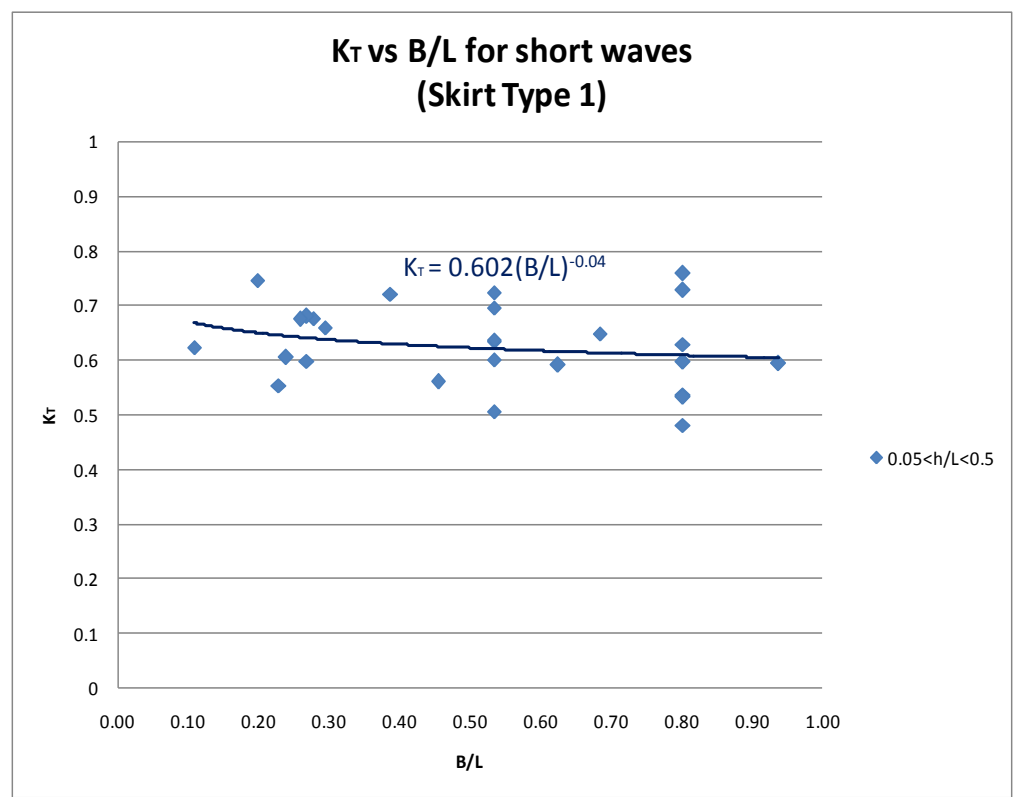

Figure $14 \mathrm{~K}_{\mathrm{T}}$ vs $\mathrm{B} / \mathrm{L}$ for medium depth criteria on PSB skirt type 1 investigation, where $\mathrm{B}$ is total width of structure and $\mathrm{L}$ is wavelength.

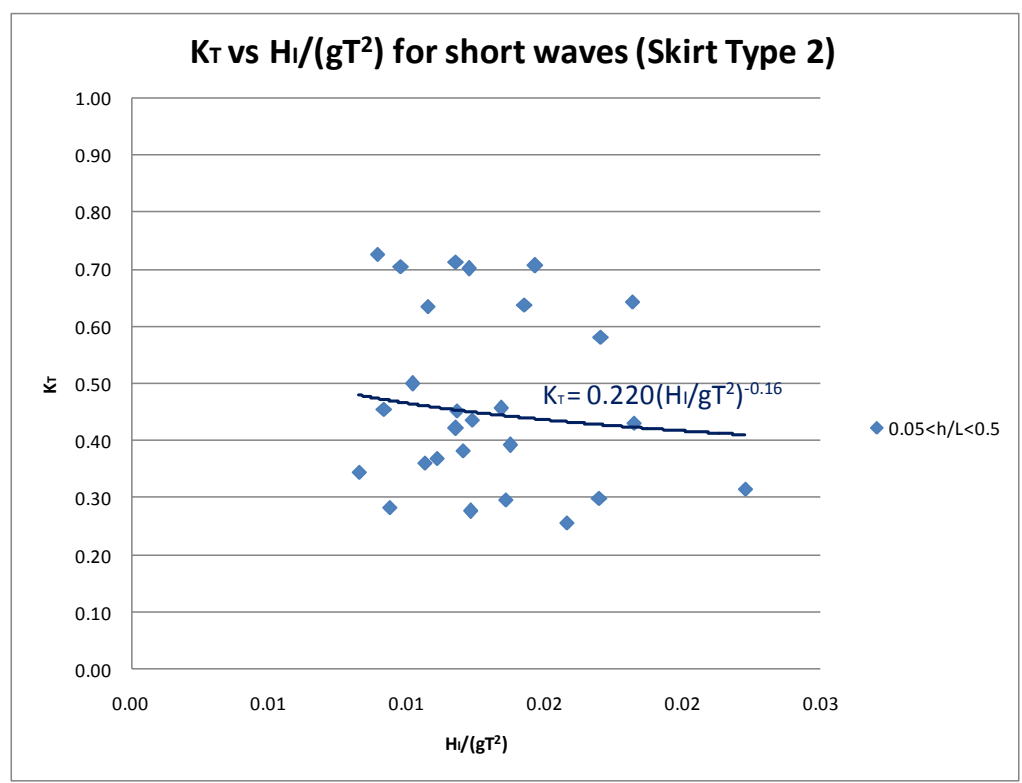

Figure $15 \mathrm{~K}_{\mathrm{T}}$ vs $\mathrm{H}_{\mathrm{i}} /\left(\mathrm{gT}^{2}\right)$ for medium depth criteria on PSB skirt type 2 investigation. 


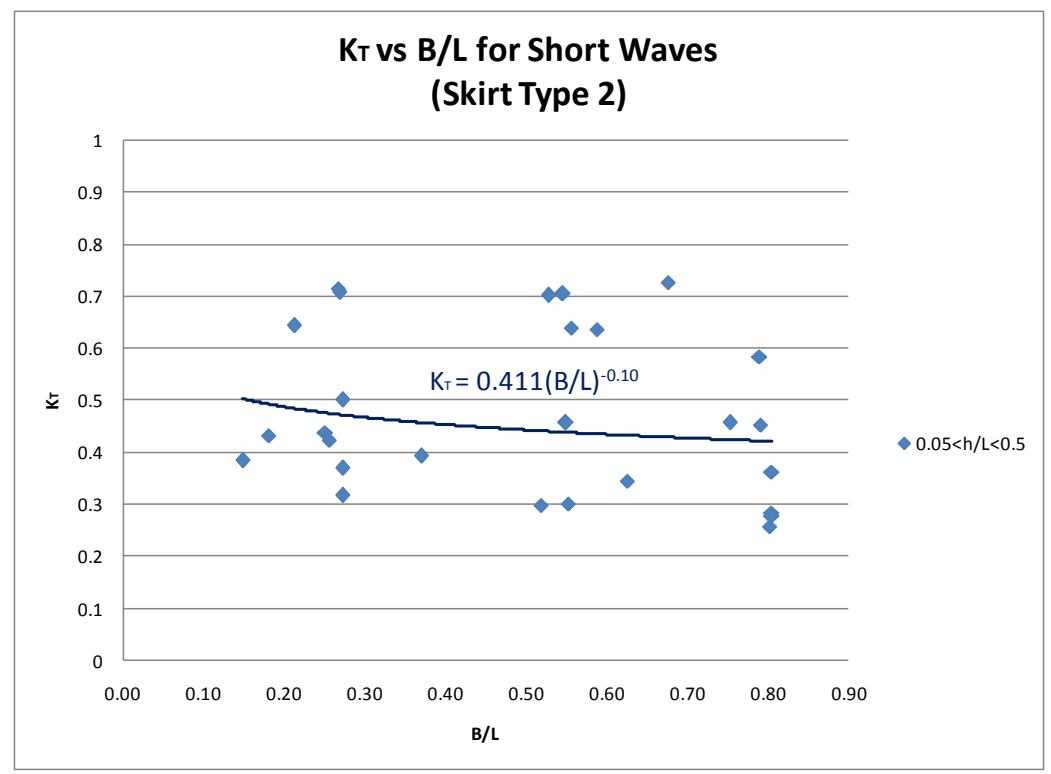

Figure $16 \mathrm{~K}_{\mathrm{T}}$ vs $\mathrm{B} / \mathrm{L}$ for medium depth criteria on PSB skirt type 2 investigation, where $\mathrm{B}$ is total width of structure and $\mathrm{L}$ is wavelength.

\section{$5 \quad$ Comparisons with Related Research}

The results of $\mathrm{K}_{\mathrm{T}}$ from this study are compared to similar studies before ([4]; $[5])$.

1) Research on submerged breakwater, which made of artificial coral reefs, or called as Hemispherical Shape Artificial Reefs (HSAR) by Armono and Hall [4].

The influence of water depth, incident wave height and period and reef configuration on wave transmission were investigated. Wave height reduction was found to be influenced by the wave steepness, depth of submergence, and reef geometry. About $60 \%$ of the incoming wave energy was reduced on average.

The research configuration (by Armono and Hall) can be seen in Figure 17, where $B$ is the total width of artificial reefs, $h$ is the distance from the bottom of water to the top of artificial reefs, while $d$ is water depth. In the study, Armono and Hall put the hollow artificial reef on the solid structure (as shown in Figure 18) [4]. 


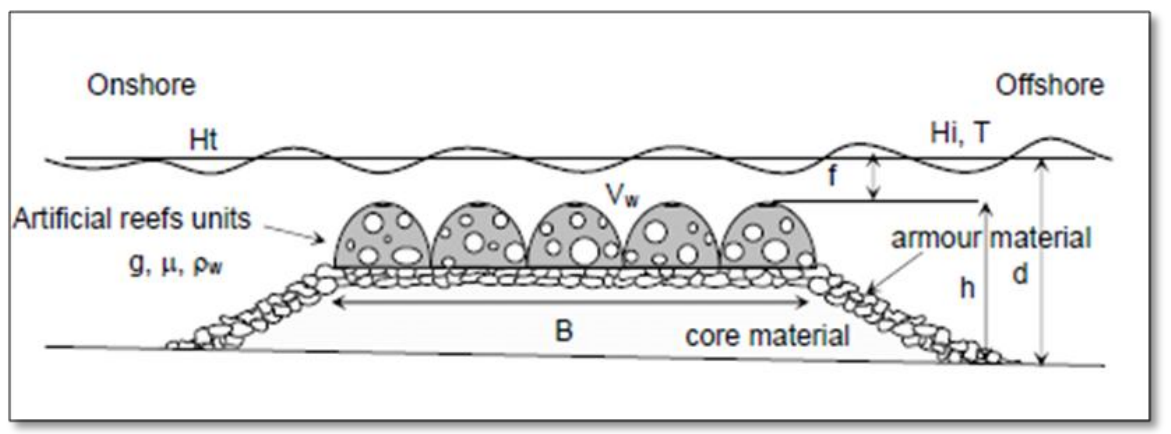

Figure 17 Sketch of HSAR investigation by Armono and Hall [4].

Figure 18 shows the results of HSAR investigation [4].

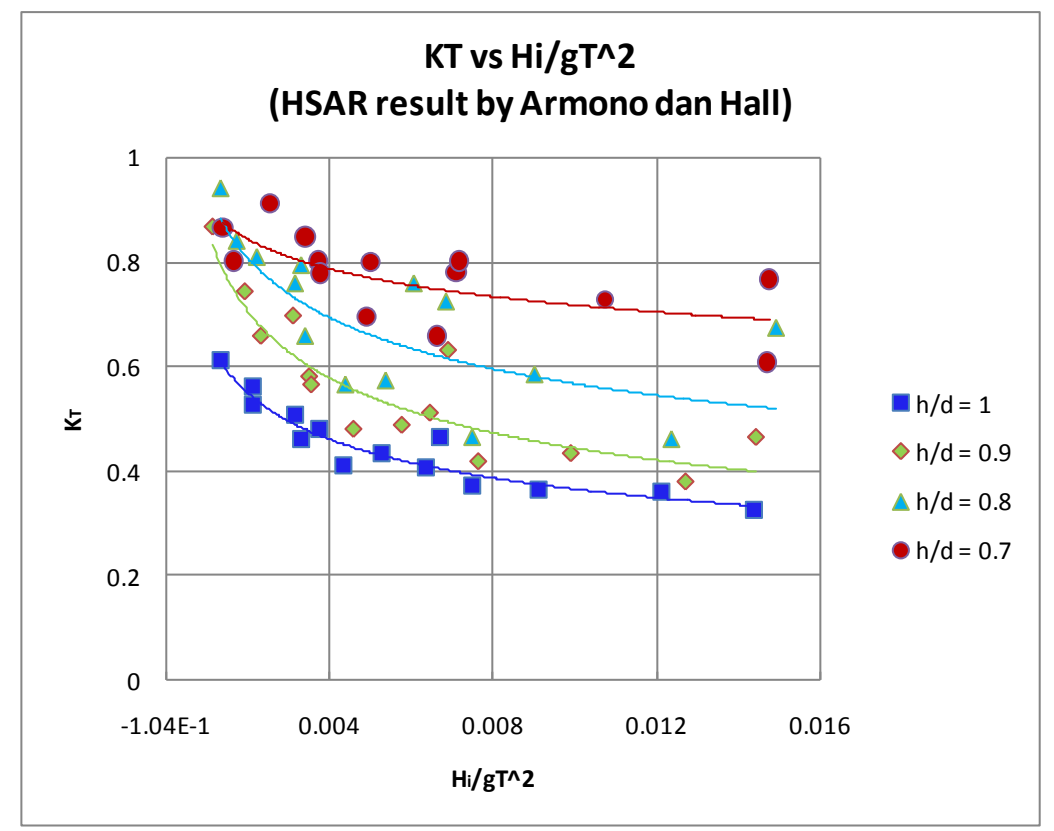

Figure 18 Sketch of HSAR investigation by Armono and Hall for each h/d.

In Figure 18, Armono and Hall separated results for each h/d conditions, while Figure 19 shows the result of investigation where h/d is collected for all conditions (this figure was made by author to compare it to PSB result) and then it was compared to current study (for each type of skirt). 


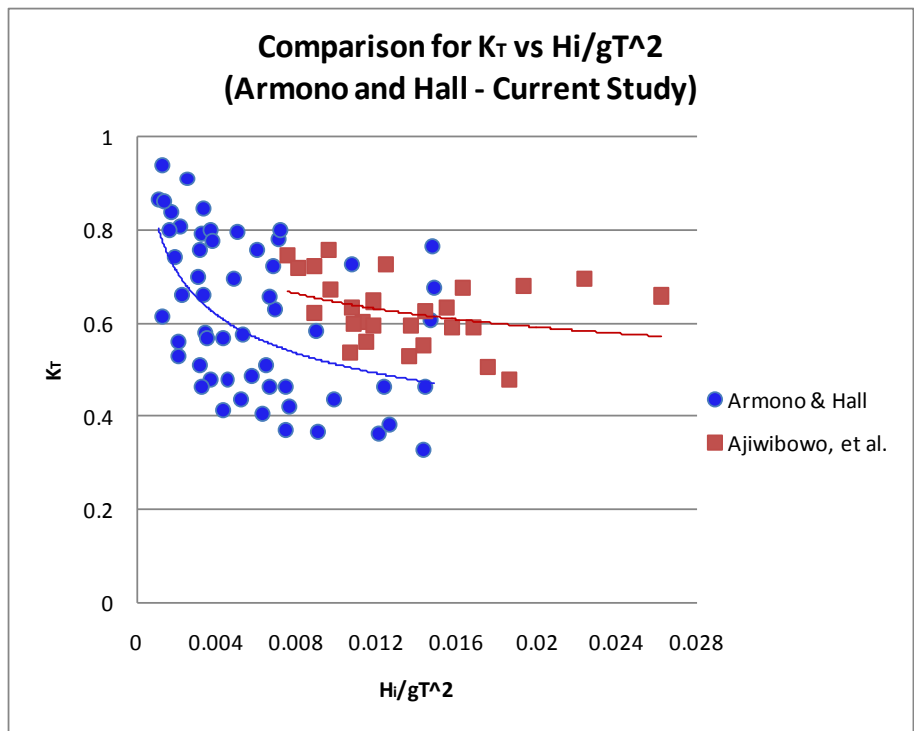

(a)

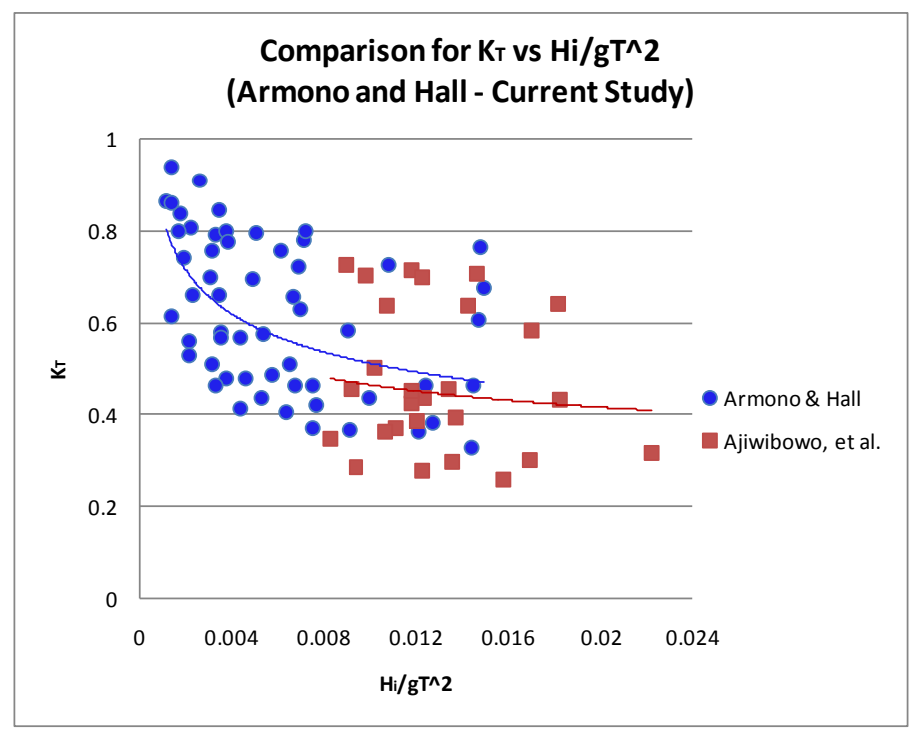

(b)

Figure 19 Comparison for $\mathrm{K}_{\mathrm{T}}$ vs $\mathrm{Hi} /(\mathrm{gT})^{2}$ between $\mathrm{HSAR}$ and PSB investigation, for: a) Skirt Type 1, b) Skirt Type 2. 
Based on the comparison in Figure 19, different type of skirt has different results,

i. In skirt type 1 result (see Figure 19a), it can be concluded that the value of $K_{T}$ for HSAR is smaller than the $K_{T}$ for PSB. This is because the solid structure which is used as a base of HSAR unit (Figure 16) also played an important part in dissipating the wave energy, while the PSB structure there is no massive structure on the lower side. The absence of solid structures at the PSB are intended to reduce costs. The solid structure would make the PSB costly when it was placed in deep water.

ii. In skirt type 2 result (see Figure 19b), it can be concluded that the value of $\mathrm{K}_{\mathrm{T}}$ for PSB is smaller by $\mathrm{K}_{\mathrm{T}}$ result for HSAR. It shows the performance of PSB with skirt type 2 is better than HSAR.

2) Perforated breakwater investigation by Ariyarathne [5]

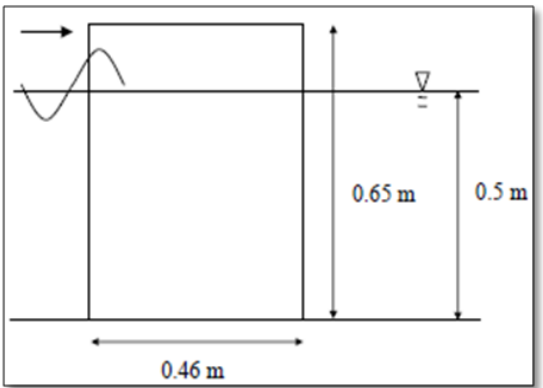

(a)

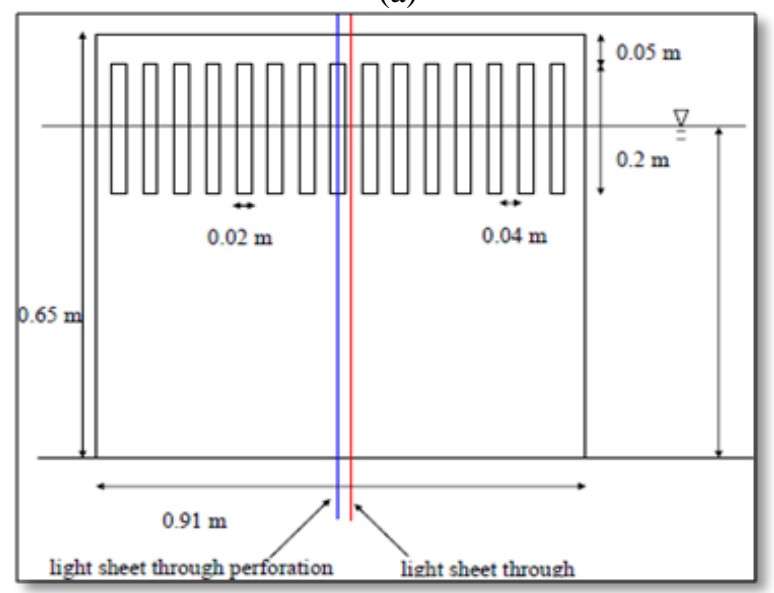

(b)

Figure 20 Sketch of perforated breakwater by Ariyarathne [5]. 
Ariyarathne [5] tested the perforated breakwater, where the breakwater structure consists of a solid structure from the bottom up to the top of the breakwater with perforation part in the upper structure (see Figure 20).

In Figure 20 (b), it can be seen that the solid breakwater is more dominant than perforation.

Figure 21 shows the results of investigation by Ariyarathne on the breakwater perforated [5].

From the results it is clear that reflection, transmission and energy dissipation depends on the parameter $\mathrm{B} / \mathrm{L}$, where $\mathrm{B}$ is the width of the structure and $\mathrm{L}$ is the wavelength. For the tested wave conditions, the energy dissipation lies between $56 \%$ and $78 \%$, and for more than $75 \%$ of the tested cases the energy dissipation is above $69 \%$. This means the structure is very effective in energy dissipation. While the reflection coefficient decreases with increasing $\mathrm{B} / \mathrm{L}$ till about 0,225 , then it starts increasing. The minimum reflection coefficient occurs at $\mathrm{B} / \mathrm{L} \approx 0,2-0,25$. This agrees well with Kondo [6], Suh, et al. [7] and Hagiwara [8].

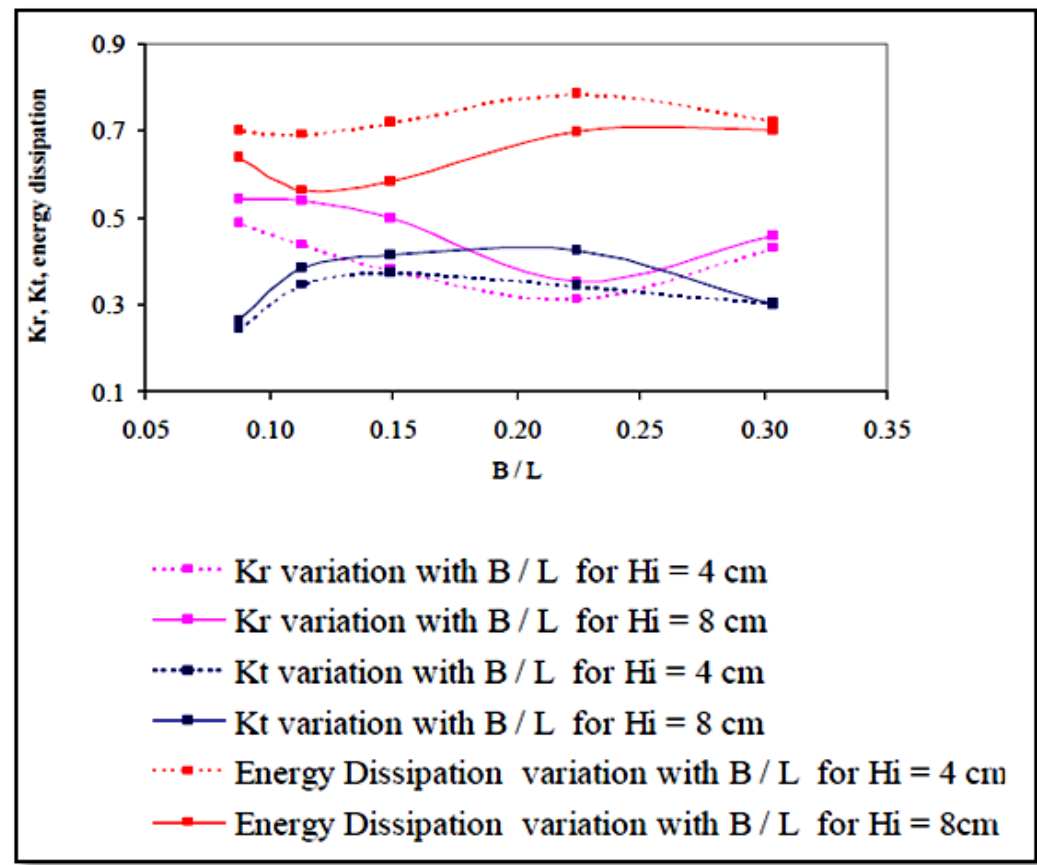

Figure $21 \mathrm{~K}_{\mathrm{T}}$ vs $\mathrm{B} / \mathrm{L}, \mathrm{K}_{\mathrm{r}}$ vs $\mathrm{B} / \mathrm{L}$, and energy dissipation for the perforated breakwater, by Ariyarathne [5]. 
Plot for transmission coefficient $\left(\mathrm{K}_{\mathrm{T}}\right)$ is retrieved from Figure 21 and compared to current study (presented in Figure 22).

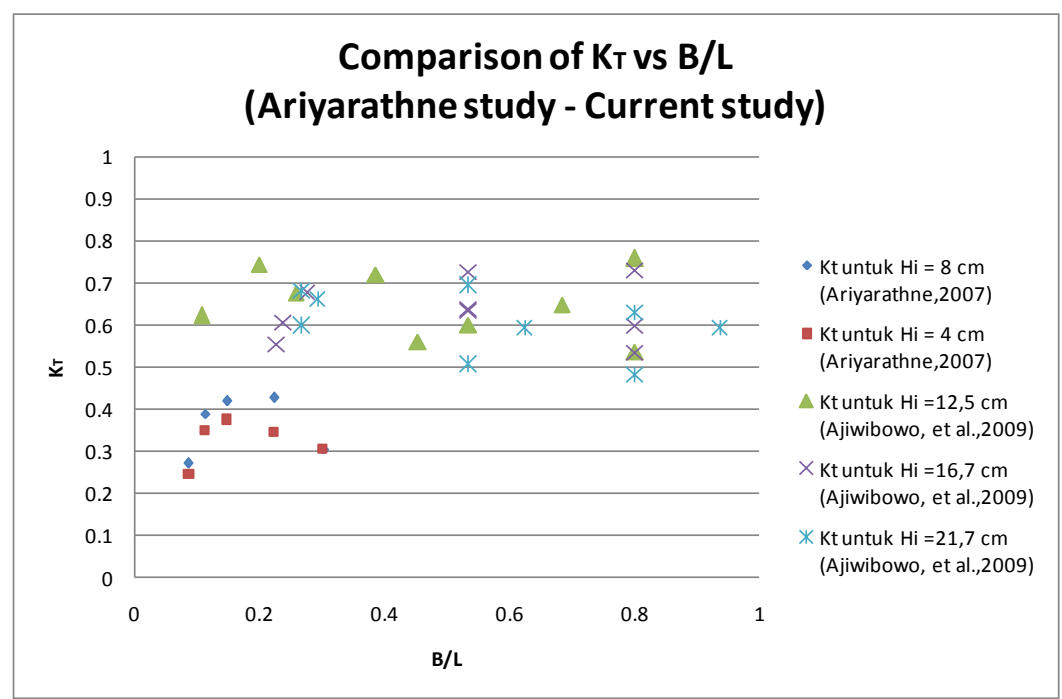

(a)

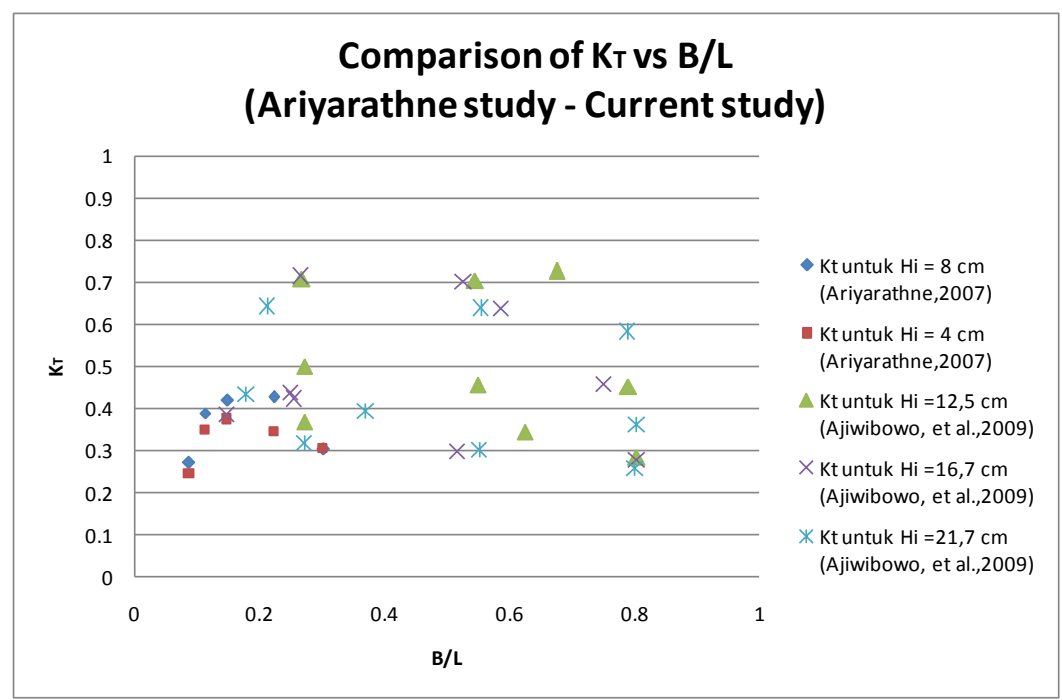

(b)

Figure 22 Comparison for $K_{T}$ vs $B / L$ between Ariyarathne and current investigation, for: a) Skirt Type 1, b) Skirt Type 2. 
Based on the comparison in Figure 22, it can be concluded that the value of $\mathrm{K}_{\mathrm{T}}$ by Ariyarathne is smaller than the $\mathrm{K}_{\mathrm{T}}$ by current study. This is because the research by Ariyarathne was using solid breakwater which is much more dominant than its perforation (Figure 20). For perforated breakwater by Ariyartahne, the solid part from the bottom until the top is certainly very effective in dissipating wave energy. But it less economical. Contrary to the perforated breakwater by Ariyarathne, the perforation of the PSB structure is much more dominant than the solid part, so it is more appropriate when used in deep water [5].

\section{Conclusions}

According to Figures 10-12, it can be seen that the bigger the value of draft (S) of skirt, the smaller value of $K_{T}$ or more dissipations on wave energy within the system. The smaller the $\mathrm{K}_{\mathrm{T}}$ coefficient means the better the performance of the breakwater. The skirt model 2 is more effective than skirt model 1. The effectiveness of breakwater for short waves $\left(T_{p}=4 \mathrm{~s}\right.$ or $\left.T_{m}=1.2 \mathrm{~s}\right)$. For short waves, it can dampen the waves from $30 \%$ to $70 \%$.

Length of chamber (Lc) influence the performance of breakwater. $\mathrm{K}_{\mathrm{T}}$ value become bigger (the performance of breakwater is less effective) when Lc is smaller. At this research, Lc prototype $=6 \mathrm{~m}$ is the most effective for the performance of breakwater, while the number of Chambers also important that is more chambers rooms more effective the PSB is.

\section{$7 \quad$ Recommendations for Future Research}

The future reasearch for the PSB will be of larger scale model (larger than 1:12) such as 1:5 or even full scale model. This larger scale model should be conducted in the wave flume that is sufficient to conduct such scale. Using the larger scale model, results are more accurate. Wider range of wave heights, periods and water depths can also be conducted to cover long wave situation.

The results of this physical modeling is becoming more interesting if compared with the numerical model. The research of making numerical software of PSB should be conducted for wider applications for wider spectrum of wave frequencies. 


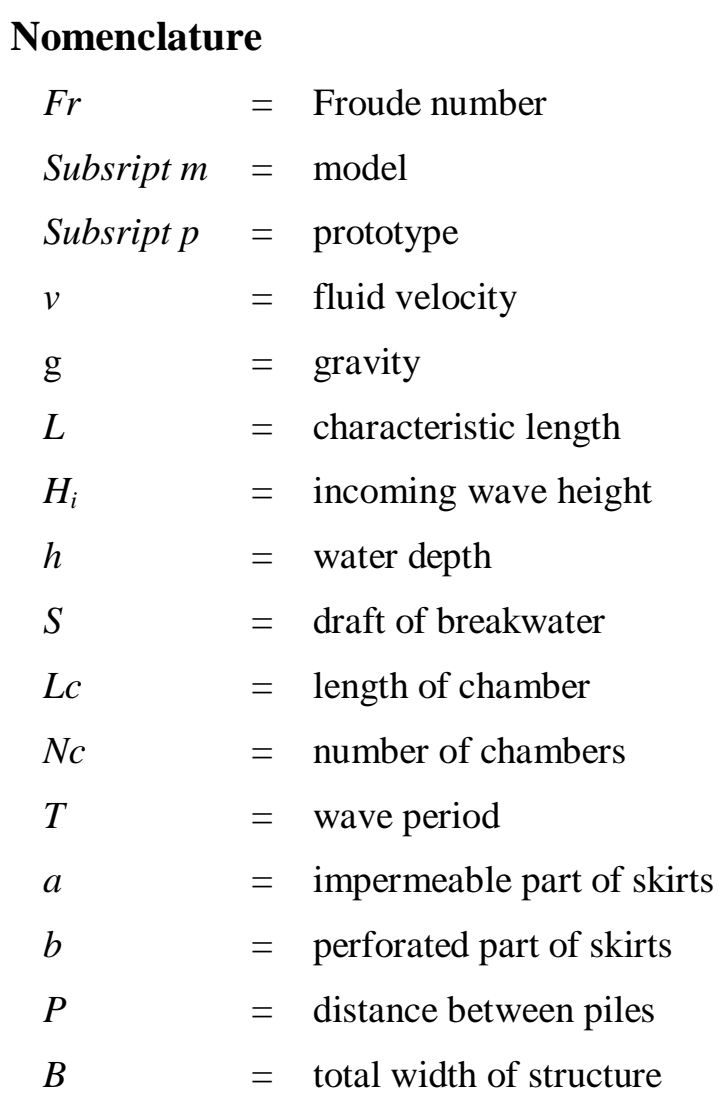

\section{References}

[1] Jarlan, G.E., A Perforated Vertical Wall Breakwater, Dock Harbour Auth. XII, 486, pp. 394-398, 1961.

[2] Quinn, A., Design and Construction of Ports and Marine Structures, New York: McGraw Hill, 1972.

[3] Bergmann, H., Kudella, M. \& Oumeraci, H., Wave Loads and Pressure Distribution On Permeable Vertical Walls, ASCE, (Copenhagen, Denmark, 26, pp. 2, International Conference Coastal Engineering, 1998.

[4] Armono, H.D. \& Hall, K.R, Wave Transmission On Submerged Breakwaters Made Of Hollow Hemispherical Shape Artificial Reefs, Canadian Coastal Conference, pp. 1-13, 2002.

[5] Ariyarathne, H.A.K.S., Efficiency of Perforated Breakwater and Associated Energy Dissipation, Civil Engineering of Texas A\&M University, 2007. (Thesis) 
[6] Kondo K., Analysis of Breakwaters Having Two Porous Walls, pp. 962977, Proc. Coastal Structures '79 Alexandria, 1979.

[7] Suh K.D., Choi, J.C., Kim, B.H., Park, W.S. \& Lee, K.S., Reflection of Irregular Waves from Perforated-Wall Caisson Breakwaters, Coastal Engineering, 44, 141-151, 2001.

[8] Hagiwara K., Analysis of Upright Structure for Wave Dissipation Using Integral Equation, Conf. on Coastal Engineering A.S.C.E, 1984.

[9] Bloxam, M., Maxted G. \& Murray J., Wave Energy Dissipating Wharf: Raffles Marina Breakwater, Singapore, Coasts \& Ports Australasian Conference, 95, 2003. 